\title{
Genital infections in women attending a genito-urinary clinic in Harare, Zimbabwe
}

\author{
P R Mason, L Gwanzura, A S Latif, E Marowa
}

\begin{abstract}
One hundred women attending a sexually transmitted diseases clinic in Harare were examined for presenting features and genital infections. The most common presenting symptoms were of discharge, lower abdominal pain and dysuria, and on examination signs of discharge, inflammation, haemorrhage or ulcers/erosions were noticeable in all women. Fourteen women had genital warts. Pathogens were detected in $95 \%$ of patients. Gonococcal infection occurred in 19 women, with $60 \%$ of the strains isolated being penicillinase producing. Yeasts were detected in specimens from 25 women while chlamydial infection appeared to be rare, evidence of infection being detected in only eight women. Sera from 44 women were positive by the RPR test and sera from 33 women were positive by TPHA. Gardnerella vaginalis was isolated from 48 women, Group B streptococci from 37 women, and Trichomonas vaginalis from 32 women.
\end{abstract}

Infection with one or more pathogenic organism is generally the cause of vaginal inflammation and discharge. ${ }^{1}$ Ascending infection from the lower genital tract of women may lead to serious problems for health and reproductive capacity ${ }^{2}$ and since many of these organisms are transmitted by sexual intercourse, a knowledge of the prevalent sexually transmitted diseases (STD) in a population is an important aspect of health care.

Numerous studies have been carried out in developed countries to document both the "normal" vaginal flora ${ }^{34}$ and the flora associated with disease. ${ }^{15}$ Relatively little is known of the genital flora of women in developing countries, though data from Africa suggest that STDs are common even in women with no overt signs of infection. ${ }^{6}$ Such studies have been limited in the main to pregnant women

Department of Medical Microbiology and Medicine, University of Zimbabwe Medical School, Harare Peter R Mason, Lovemore Gwanzura, Ahmed S Latif The City Health Department, Harare

Evaristo Marowa presenting at referral hospitals, and there is little information on prevalent organisms in women presenting with genital infections at the clinic level.

This study was designed to determine microbial pathogens in the vagina of 100 women attending an STD clinic in Mbare, a high density housing suburb of Harare. Data were also collected on aspects of clinical and laboratory diagnosis of such infections.

\section{Patients and methods}

1. PATIENTS

The study population comprised women attending the Genito-Urinary Centre in Mbare. According to reports from the Municipal Officer of Health for the city, about 15000 people attend this clinic per year of whom $25 \%$ are women. ${ }^{7}$

Women were enrolled into the study provided they attended before $1100 \mathrm{~h}$ on Monday, Tuesday or Wednesday of each week during the study period, these being the days when a member of the team could collect specimens and ensure their processing in the laboratory the same day. Women with severe genital warts were excluded because of the bleeding and discomfort associated with obtaining specimens from them, but women were otherwise unselected and enrolment continued until 100 had been investigated.

All of the women enrolled in the study gave their consent for specimens to be collected.

\section{DATA, SPECIMEN COLLECTION AND LABORATORY TECHNIQUES}

After a history taking and a general medical examination, the cervix and vaginal walls were inspected and bimanual vaginal examination was carried out. Special note was taken of any obvious discharge, bleeding, ulcers, warts and erosions.

Two endocervical swabs were taken, one was used to inoculate Thayer-Martin agar for selection of gonococci and the other was inoculated into chlamydia transport media. Two high vaginal swabs were also collected, one being inoculated into transport media ("Transcult", BBL, USA) for maintenance of gardnerella and streptococcus, and the other into Diamond's medium for trichomonas. A urethral swab was taken and inoculated onto Thayer-Martin medium. Blood was then collected for syphilis serology. 
All plates and media were inoculated at the time of examination and were transported to the laboratory within 4 hours. Standard laboratory methods were used to isolate organisms. Trichomonas vaginalis was identified by microscopy of cultures on receipt in the laboratory and again after 24,48 and $72 \mathrm{~h}$ incubation in air at $37^{\circ} \mathrm{C}$.

Gonococcal penicillinase activity was determined using commercial test strips (Intralactam, Mast, UK).

Beta haemolytic Gram positive cocci that were catalase negative were grouped using commercial streptococcal antisera (Streptex, Wellcome, UK). Gardnerella vaginalis were grown on selective media (Selectatab, Mast, UK) and identified on criteria described by Ison et al. ${ }^{8}$

Chlamydial antigen was detected using a commercial EIA test (Chlamydiazyme, Abbott, USA). Blood specimens were tested for syphilis using both nonspecific (RPR) and specific (TPHA) tests.

\section{Results}

1. SOCIAL/MEDICAL HISTORY

Of the 100 women included in the study, 86 were married, 10 single and four divorced. Only five women were in paid employment. All of the women gave their residential address as one of the high density suburbs of Harare.

The ages of the women ranged from $15 \mathrm{yr}$ to $45 \mathrm{yr}$, with 60 women being under 25 years of age. Seventy eight women had children (range 1-10, median 2), 22 were pregnant at the time of examination and 23 were breast feeding and had not menstruated since their last pregnancy.

Fifty nine women gave a history of previous genital infection, with vaginal discharge being noted in $\mathbf{4 0}$ $(68 \%)$ of these, lower abdominal pain in $14(24 \%)$, genital sores or syphilis in $4(7 \%)$ and genital warts in $1(2 \%)$.

\section{SIGNS AND SYMPTOMS}

The four most common complaints were of discharge (75), lower abdominal pain (72), dysuria (50) or dysmennorrhoea (40). At the time of examination all the women complained of at least two of these, 23 women complained of three and 18 women of all four. In $35(40 \%)$ of the cases where a discharge was noted on examination it was described as white and in 11 $(13 \%)$ cases as yellow, in other cases being either clear or grey. In $20(23 \%)$ of cases the discharge was noted as being watery, in $22(25 \%)$ as purulent, in 13 $(15 \%)$ as having an offensive odour, in nine $(10 \%)$ as frothy and in five $(6 \%)$ as mucoid.

Mild genital warts were seen on vaginal examination of 14 women. Ulcers and/or erosions were recorded in 18 women though there was no detectable relationship with any one pathogen.
Table 1 Prevalence of vaginal infections in 100 women attending an STD clinic in Harare

\begin{tabular}{ll}
\hline Organism & No of women \\
\hline G vaginalis & 48 \\
Group B streptococcus & 37 \\
Taginalis & 32 \\
Yeasts & 25 \\
$N$ gonorrhoeae & \\
PPNG & 13 \\
non-PPNG & 6 \\
trachomatis & 8 \\
\hline
\end{tabular}

\section{ORGANISMS}

Pathogens were isolated from the genital tract of 95 women, with 35 having one pathogen, 32 having two pathogens, 20 having three and eight four or more. The prevalence of the various infections detected is shown in table 1.

Thirty two women were found to harbour $T$ vaginalis, with $3(9 \%)$ infections being diagnosed on initial microscopy alone, $16(50 \%)$ by both microscopy and culture and $13(41 \%)$ only after culture. Trichomonal infection was associated with a purulent, frothy or offensive discharge, but not with other signs or symptoms.

Yeast cells were identified on microscopy of specimens from 25 women. An association between yeast infection and a yellow discharge was noted, with $7 / 11(60 \%)$ of women with such a discharge showing the presence of yeast compared with 18/77 $(23 \%)$ of specimens from women with other types of discharge $\left(\chi^{2}=7 \cdot 7, \mathrm{p}<0.05\right)$.

Neisseria gonorrhoeae was isolated from 19 women, with $13(60 \%)$ of the isolates being PPNG. A purulent discharge was recorded in eight $(42 \%)$ women with gonococcal infection compared with 15 $(19 \%)$ women with other infections $\left(\chi^{2}=8 \cdot 4\right.$, $\mathrm{p}<0.01$ )

There was a strong association between gonococcal infection and trichomonal infection, $10(53 \%)$ women having both infections. By contrast only 9 $(13 \%)$ of gonococci-negative women harboured $T$ vaginalis $\left(\chi^{2}=4.6, p<0.05\right)$.

"Clue cells" were detected in Gram stained films from 57 women, and $G$ vaginalis was cultured from

Table 2 Isolation of organisms from women at an STD clinic in Harare: Relationship to clue cells

\begin{tabular}{|c|c|c|c|c|}
\hline & \multirow[b]{2}{*}{$\begin{array}{l}\text { Clue cell } \\
+v e\end{array}$} & \multicolumn{3}{|c|}{ No $(\%)$ women with organism } \\
\hline & & $\begin{array}{l}\text { Clue cell } \\
\text {-ve }\end{array}$ & $\chi^{2}$ & $p$ \\
\hline $\begin{array}{l}G \text { vaginalis } \\
T \text { vaginalis } \\
N \text { gonorrhoeae } \\
\text { Yeasts } \\
\text { Group B Strep }\end{array}$ & $\begin{array}{r}36(63) \\
16(28) \\
6(11) \\
14(25) \\
20(35)\end{array}$ & $\begin{array}{l}12(28) \\
16(37) \\
13(31) \\
11(26) \\
17(40)\end{array}$ & $\begin{array}{c}12 \cdot 2 \\
0.94 \\
6.18 \\
0.01 \\
0.20\end{array}$ & $\begin{array}{l}<0.001 \\
\text { NS } \\
<0.05 \\
\text { NS } \\
\text { NS }\end{array}$ \\
\hline
\end{tabular}


48. There was a strong association between the presence of clue cells and $G$ vaginalis but not with other pathogens in the genital tract (table 2).

The isolation of $G$ vaginalis was more common in women complaining of dysuria (31/50 compared with $17 / 50$ women with no dysuria, $\chi^{2}=7.9$, $\mathrm{p}<0.01)$ and of discharge (41/75 compared with $7 / 25$ women with no discharge, $\chi^{2}=5.3, p<0.05$ ) though there was no detectable association between $G$ vaginalis infection and an offensive discharge.

Lancefield Group B streptococci (GBS) were isolated from 37 women, though carriage of this organism was not associated with any of the signs or symptoms recorded in this study.

Chlamydial antigen was detected in specimens from only eight women. Forty four sera were positive by either TPHA or RPR, with 17 positive by both tests, 16 positive by TPHA only and 11 positive by RPR only.

\section{Discussion}

In this study we have recorded the common pathogens in 100 African women attending a genitourinary clinic that serves a high density suburb of Harare. We were not able to compare the findings in these women with "controls" because of the difficulty of obtaining specimens from healthy women in this cultural and social setting. The only locally comparable data then are from studies of the genital flora of pregnant women at local maternity hospitals, ${ }^{69}$ and in this regard we would note that over half of the women we investigated were either pregnant or were post-natal cases.

The most common pathogen we were able to detect was $G$ vaginalis. The prevalence we found was similar to that described at a clinic in Nigeria ${ }^{10}$ though data from elsewhere in Africa are scant. Infection was associated with dysuria and discharge, though by no means all of the women harbouring this organism presented with these symptoms. We did not attempt to quantify organisms, and others have demonstrated more convincingly the role of this bacterium in disease using quantitative methods. ${ }^{11}$ The strong correlation between $G$ vaginalis infection and the presence of clue cells confirms the diagnostic value of microscopy for these cells even in Africa where other infections are common. In our experience the detection of clue cells had a sensitivity of $75 \%$ and a specificity of $60 \%$ when compared with culture for $G$ vaginalis.

The prevalence of $T$ vaginalis ( $32 \%$ ) was similar to that seen in pregnant women in studies in other countries of West and Central Africa, ${ }^{10}$ though higher than in pregnant women in Harare. ${ }^{6}$ For definitive diagnosis of infection with this parasite the value of culture was confirmed.

Gonococcal infection was detected in 19 women, a prevalence similar to that seen in women with puerperal sepsis in Harare, ${ }^{12}$ but higher than recorded for pregnant women elsewhere in Africa. ${ }^{13}$ The high rate of PPNG $(60 \%)$ is comparable with that seen in isolates from men at this same clinic. ${ }^{14}$ An apparent relationship between trichomonal and gonococcal infection has been noted before, and is probably indicative of a similar mode of transmission rather than a biological association.

Finding evidence of chlamydial infection in only $8 \%$ of women was surprising, considering the prevalence $(18-22 \%)$ detected using the same methods in women with post-partum sepsis in Harare. ${ }^{12}$ While enzyme-immunoassay may be sub-optimal for diagnosis, our findings are not greatly different from those based on culture techniques elsewhere in Africa. Thus $C$ trachomatis was isolated from $5-10 \%$ of specimens from gynaecology patients in Ghana, ${ }^{15}$ $13 \%$ of women at an STD clinic in S. Africa ${ }^{16}$ and $14 \%$ of symptomatic women in The Gambia. ${ }^{17}$ Serological evidence suggests infection to be much more common ${ }^{18}$ and many infections may be too mild for women to present at health centres. Nevertheless the long term significance of infection for maternal, child and reproductive health militates for improved diagnostic tests that are applicable for use in developing nations.

Asymptomatic vaginal carriage of GBS is known to occur in over $20 \%$ of women delivering at Harare Maternity Hospital. ${ }^{6}$ The carriage rate we record here is slightly higher, but infection could not be linked to any specific sign or symptom. Nevertheless GBS has been shown to be a common organism associated with early neonatal septicaemia in Harare, ${ }^{19}$ and the significance of vaginal carriage in pregnancy in Africa needs investigation.

Serological evidence of syphilis was found in a substantial proportion of women, showing this to still be a common STD in Zimbabwe, and being considerably more prevalent than in antenatal clinics elsewhere in Africa $^{20}$ even when only TPHA positive sera are considered.

In summary our findings were that one or more pathogens could be isolated from the genital tract of over $90 \%$ of women attending a genitourinary clinic in Harare. In terms of diagnosis we did not find clincial signs and symptoms to be of great value in specific diagnosis, though microscopic examination of vaginal exudate, both as a "wet prep" and a Gram stain may be useful in detecting clue cells, trichomonads and Gram negative intracellular diplococci and these may allow the diagnosis of a substantial proportion of infections.

The invaluable assistance of the nursing staff at Mbare Genitourinary Clinic is gratefully acknowledged. We thank the MOH, Harare for permission to carry out the study at this clinic. Financial support 
was given by the University of Zimbabwe Research Board.

Address for correspondence: Dr P R Mason, Department of Medical Microbiology, University of Zimbabwe Medical School, PO Box A178, Avondale, Harare, Zimbabwe

1 Osborne NG, Grubin L, Pratson L. Vaginitis in sexually active women: Relationship to nine sexually transmitted organisms. Am J Obstet Gynecol 1982;142:962-7.

2 Muir DG, Belsey MA. Pelvic inflammatory disease and its consequences in the developing world. Am J Obstet Gynecol 1980;138:913-28.

3 Ohm MJ, Galask RP. Bacteriologic flora from the cervix of 100 pre-hysterectomy patients. Am J Obstet Gynecol 1975; 122:683-7.

4 Lindner JGEM, Plantema FHF, Hoogkamp-Koorstanje JAA. Quantitative studies of the vaginal flora of healthy women and of obstetric and gynaecology patients. J Med Microbiol 1978;11:233-41.

5 Staerfeldt F, Gundersen TJ, Halsos AM, et al. A survey of genital infections in patients attending a clinic for sexually transmitted diseases. Scand J Infect Dis Suppl 1983;40:53-7.

6 Mason PR, Katzenstein DA, Chimbira THK, Mtimavalye L. Microbial flora of the lower genital tract of women admitted in labour to Harare Maternity Hospital. Cent Afr J Med 1989; 35:337-44.

7 Annual Report of the City Health Department 1987, Harare, Zimbabwe.

8 Ison CA, Dawson SG, Hilton J, Csonka GW, Easmon CSF. Comparison of culture and microscopy in the diagnosis of Gardnerella vaginalis infection. J Clin Pathol 1982;35:550-4.
9 Ekwempu CC, Laralde RV, Egler LJ. Microbial flora of the lower genital tract of women in labour in Zaria, Nigeria. J Clin Pathol 1981;34:82-4.

10 Ogunbanjo BO. Trichomoniasis, candidosis and bacterial vaginosis. In: Osoba AO, ed. Sexually Transmitted Diseases in the Tropics. London: Bailliere-Tindall, 1987.

11 Holmes KK. Lower genital tract infections in women: Cystitis/ Urethritis vulvovaginitis and cervicitis. In: Holmes KK, Mardh P-A, Sparling PF, Weissner JP, eds. Sexually Transmitted Diseases. New York: McGraw-Hill Book Co, 1984.

12 Mason PR, Katzenstein DA, Chimbira THK, Mtimavalye L. Vaginal flora of women admitted to hospital with signs of sepsis following vaginal delivery, Caesarian Section or abortion. Cent Afr J Med 1989;35:344-51.

13 Meheus A. Gonorrhoea. In: Osoba AO, ed. Sexually Transmitted Diseases in the Tropics. London: Bailliere-Tindall, 1987.

14 Mason PR, Gwanzura L. Characterisation by plasmid profile, serogroup and auxotype of Neisseria gonorrhoeae from Harare, Zimbabwe. Genitourin Med 1988;64:303-7.

15 Bentsi C, Klufio CA, Perine PL, et al. Genital infections with Chlamydia trachomatis and Neisseria gonorrhoeae in Ghananian women. Genitourin Med 1985;61:48-50.

16 Ballard RC, Fehler HG. Chlamydial infections of the eye and genital tract in southern Africa. $S$ Afr Med J 1986; 70(Suppl):76-9.

17 Mabey DCW, Whittle HC. Genital and neonatal chlamydial infection in a trachoma endemic area. Lancet 1982;ii:300-1.

18 Forsey T, Darougar S. Chlamydial infections. In: Osoba AO, ed. Sexually Transmitted Diseases in the Tropics. London: Bailliere-Tindall, 1987.

19 Nathoo K, Mason PR, Chimbira THK. Neonatal septicaemia in Harare: aetiology and risk factors. Cent Afr J Med (in press).

20 Arya OP. Early infectious and late syphiliis. In: Osoba AO, ed. Sexually Transmitted Diseases in the Tropics. London: Bailliere-Tindall, 1987.

Accepted for publication 21 December 1989 